\title{
Technoheritage: ciencia, tecnología y empresa al servicio del patrimonio cultural
}

La Red de Ciencia y Tecnología para la Conservación de Patrimonio Cultural ${ }^{1}$ funciona desde 2011. Aglutina a sesenta y siete grupos distribuidos en tres áreas de actividad: grupos de investigación del CSIC y universidades españolas; instituciones culturales, fundaciones y museos; y empresas del sector. La red pretende fomentar la colaboración entre los actores del sistema ciencia-tecnología-empresa para la puesta en común de ideas y experiencias que ayude a la resolución de problemas y permita la transferencia de tecnología. El objetivo común: contribuir a la conservación del patrimonio cultural. En 2019 celebra su cuarto congreso en Sevilla con la participación activa del IAPH.

Manuel Castellano Román, María del Pilar Ortiz Calderón, Francisco Pinto Puerto, Emilio Cano Díaz | dirección y coordinación Technoheritage 2019

URL de la contribución <http://www.iaph.es/revistaph/index.php/revistaph/issue/view/4254>

Los avances científicos y tecnológicos que inciden sobre la tutela del patrimonio cultural se producen de forma cada vez más acelerada. Sistemas de auscultación, prospección y análisis de su materialidad, de control de las diversas magnitudes que lo caracterizan, o de representación y modelización, han adquirido una dimensión inédita en las últimas décadas. Las tecnologías digitales no sólo mejoran cuantitativa y cualitativamente las posibilidades de aproximación al legado histórico, sino que permiten nuevas formas de interpretarlo y difundirlo. Se abren nuevos horizontes que permiten incorporar miradas muy diversas sobre lo patrimonial, procedentes de disciplinas cada vez más especializadas, con sus propios lenguajes y algoritmos. Resulta necesario interpretar las grandes masas de datos que ofrecen estas disciplinas y, a la vez, abordar las dificultades de gestión y garantías de permanencia de una cantidad de información cada vez más especializada, que además puede evolucionar en tiempo real. Esta visión multidisciplinar y tecnológica de la tutela patrimonial la enriquece, pero a la vez la complejiza, situándola ante el reto de su gestión integrada.

Los sesenta y siete grupos que integran la Red Technoheritage, en funcionamiento desde 2011 , se distribuyen en tres áreas de actividad: investigación (del Consejo Superior de Investigaciones Científicas y de diferentes universidades españolas); instituciones cultu- rales, fundaciones y museos; y empresas del sector. $Y$ las acciones que llevan a cabo se pueden agrupar en cuatro categorías: 1) impulsar a los diferentes grupos mediante la coordinación de actividades, en la actualidad dispersas en diferentes áreas científicas; 2) obtener el reconocimiento institucional de las actividades y la promoción de los grupos miembros a través de acciones prioritarias; 3) fomentar la colaboración entre los grupos de cara a crear una masa crítica mediante su asociación en proyectos de investigación nacionales y europeos; y 4) crear una proyección adecuada de la Red mediante la colaboración con grupos europeos similares para facilitar el acceso a consorcios y proyectos internacionales.

\section{Un congreso internacional sobre el impacto de lo digital en la tutela del patrimonio}

La Red Technoheritage, perteneciente al CSIC, ampara la celebración del International Congress Science and Technology for the Conservation of Cultural Heritage, cuya cuarta convocatoria se celebrará en Sevilla ( 26 al 30 de marzo de 2019), colaborando en su organización y difusión el Instituto Andaluz del Patrimonio Histórico. La convocatoria anterior se celebró en Cádiz en el año 2017, y tuvo una gran repercusión en el ámbito de la investigación ${ }^{2}$.

Se trata de un encuentro internacional de investigadores y especialistas de múltiples áreas vinculadas al conoci- 


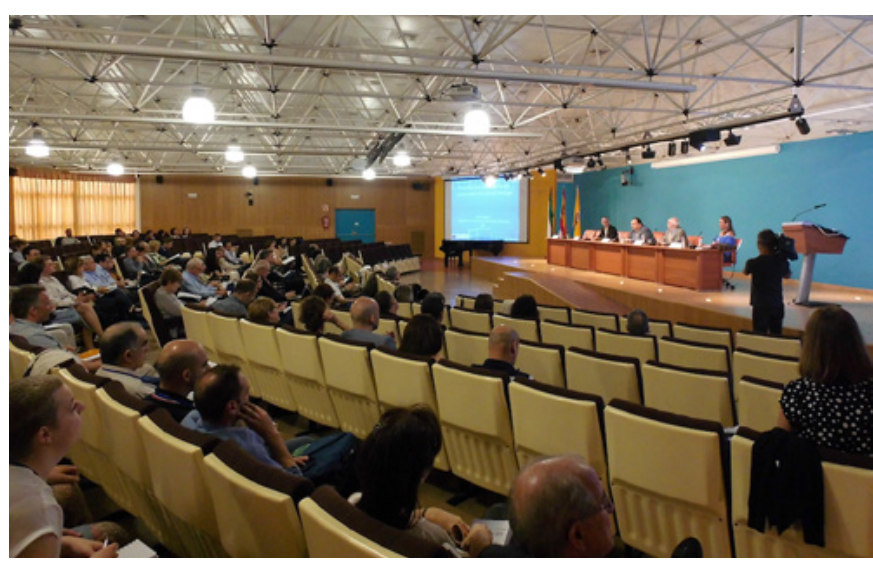

Ceremonia de apertura del III Congreso Technoheritage, 21 a 24 de 2017, Cádiz

miento y conservación del patrimonio cultural -en esta ocasión con varias secciones dedicadas al patrimonio arquitectónico- y que comparten el uso de tecnologías digitales en sus estrategias metodológicas. Se presentarán trabajos sobre nuevas tecnologías, materiales y productos y se tratarán cuestiones candentes sobre gestión, impacto social, riesgos y vulnerabilidad del patrimonio cultural $^{3}$, destacándose el papel y el impacto de las tecnologías digitales para el conocimiento, mantenimiento, gestión y difusión del mismo. Se debatirá sobre cómo los medios digitales no sólo facilitan y mejoran los procesos científicos y técnicos que tradicionalmente son usados para la tutela del patrimonio, sino cómo también modifican la manera de entender el patrimonio, percibirlo y transmitirlo, y ofrecen un nuevo horizonte de estrategias para hacer más sostenible la toma de decisiones sobre su conservación en el tiempo.

El Congreso se desarrollará íntegramente en inglés y las actas serán publicadas posteriormente en una editorial externa indexada con índice de impacto. Se han recibido más de un centenar de contribuciones que serán revisadas por el Comité Científico del Congreso, formado por expertos de varias nacionalidades. Los contenidos y la estructura en áreas temáticas forman parte de las acciones recogidas en dos proyectos I+D+i financiados por el actual Ministerio de Ciencia, Innovación y Universidades, cuyos equipos se han coordinado para organizarlo conjuntamente. Se trata de los proyectos Art-Risk ${ }^{4}$, cuya investigadora principal es Pilar Ortiz Calderón, de la Universidad Pablo de Olavide, y el pro-

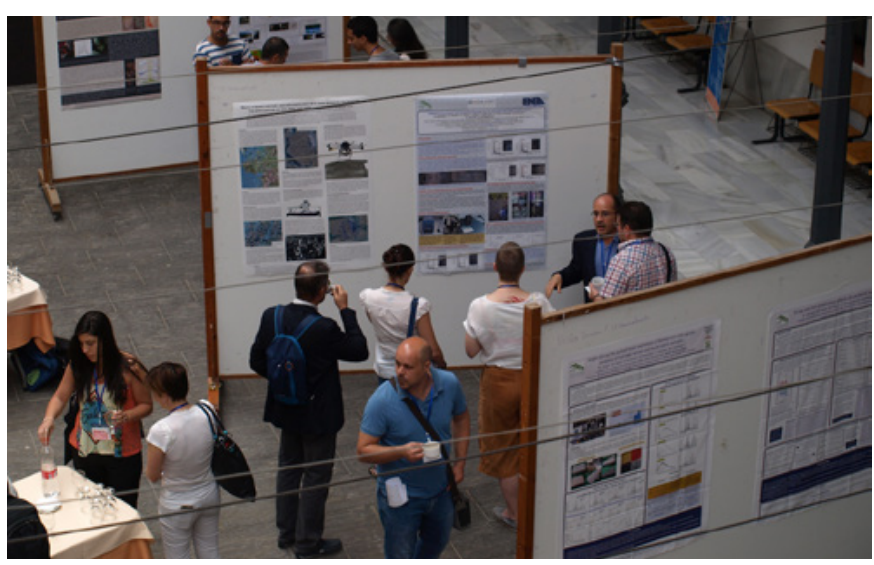

Presentación de Póster durante el III Congreso Technoheritage

yecto TUTSOSMOD ${ }^{5}$, cuyo investigador principal es Francisco Pinto Puerto, de la Universidad de Sevilla. Los IP de ambos proyectos son los directores de este evento que coordina el profesor Manuel Castellano Román.

\section{NOTAS}

1. TechnoHeritage ha contado con financiación del Ministerio de Ciencia e Innovación (Acción Complementaria HAR2010-11432-E) y de la Agencia Estatal de Investigación-Ministerio de Economía, Industria y Competitividad (Convocatoria 2016 de Redes de Excelencia, HAR21681748-REDT), y los recursos propios de los grupos participantes en la misma (http://www.technoheritage.es/).

2. Celebrado en Cádiz entre los días 21 y 24 de mayo de 2017 <https://technoheritage2017.uca.es/>.

3. Los temas de trabajo quedan recogidos en la web del congreso (congreso.us.es/technoheritage19).

4. Proyecto BIA2015-64878-R de la Universidad Pablo de Olavide (https://www.upo.es/investiga/art-risk/).

5. Proyecto HAR2016-78113-R de la Universidad de Sevilla (http://grupo.us.es/tutsosmodhum/). 